\title{
How does PISA define and measure reading literacy?
}

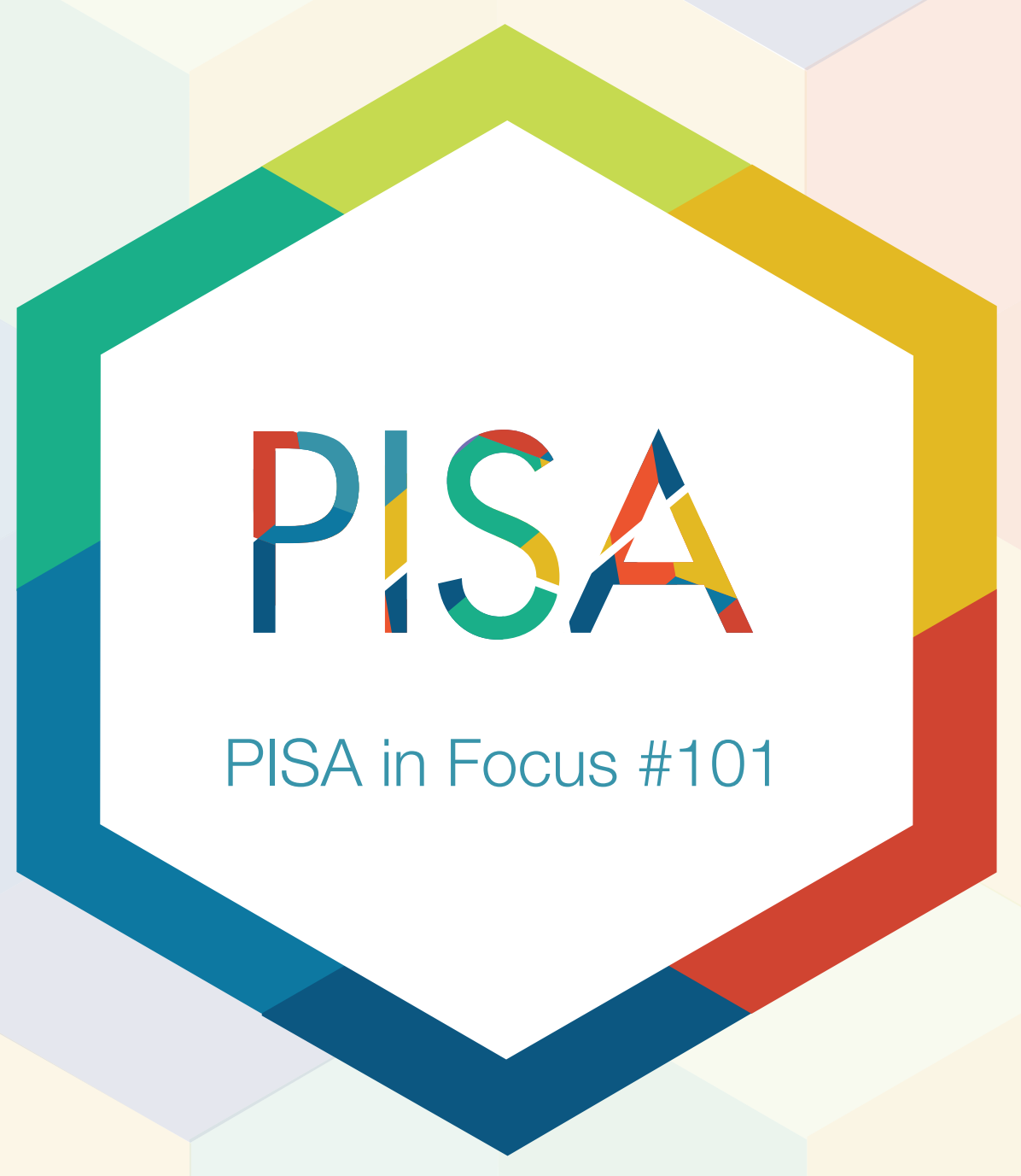




\section{How does PISA define and measure reading literacy?}

- Results from the PISA 2018 reading, mathematics and science tests will be released on 3 December 2019.

- Over 600000 15-year-old students in 79 countries and economies participated in the assessment. First-time participants included Belarus, Bosnia and Herzegovina, Brunei Darussalam, Morocco, the Philippines, Saudi Arabia and Ukraine, as well as the province of Zhejiang (China).

- PISA 2018 focused on students' proficiency in reading. A new framework for the reading assessment was developed in order to reflect how reading has changed over the past decade. In particular, the prevalence of reading in digital environments was reflected by a greater emphasis on reading multiple-source texts.

Every three years, the education community around the world eagerly awaits the release of the latest results from PISA. In addition to student proficiency in reading, mathematics and science, this December will see the publication of results on equity in education systems, school climate and students' well-being.

PISA rotates the main subject of assessment every three years, and the PISA 2018 assessment, like the PISA 2000 and 2009 assessments, focused on reading. The PISA definition of reading literacy has remained much the same over this period; in 2018, it can be summarised as understanding, using, evaluating, reflecting on and engaging with texts in order to achieve one's goals, to develop one's knowledge and potential, and to participate in society.

But how people read has changed since 2009. Reading now involves not only the printed page but also electronic formats. This has led to a proliferation in the amount of text encountered every day, making it all the more important that students be able to discern between fact and opinion, and navigate through different sources of text in order to construct meaning.

Naturally, PISA has adapted to these changes. A new framework for the reading assessment was developed for PISA 2018 and adopted in the 70 education systems that delivered the assessment on computer. This framework placed greater emphasis on the ability to find, compare, contrast and integrate information across multiple sources. In order to assess multiple-source reading, many new assessment tasks were based on texts composed of several units, each created separately by different authors or at different times. Examples of these kinds of texts would be an online forum with multiple posts, and a blog that links to a newspaper article. Computer delivery made it possible to use various digital navigation tools (such as hyperlinks or tabs) and to present such tasks within a realistic scenario, in which the amount of available text sources increases as the student progresses through the assessment.

The use of multiple sources to solve a test question should not be automatically equated with greater difficulty. Each individual source in a question (or "item") that requires multiple sources to solve might be short and written in an easy-to-understand manner; such an item would not necessarily be more difficult than an item requiring only a single source to solve, but one that is long and more complicated to read. However, the use of multiple-source texts does expand the range of reading processes and strategies PISA measures. Students now have to search for information across multiple documents; integrate information across texts to generate inferences; assess the quality and credibility of sources; and handle conflict across sources. 
Some items from the PISA 2018 assessment that have been made public illustrate the use of multiple-source texts to arrive at a correct solution. Item 7 from the released unit "Rapa Nui" asked students to state what they think caused the disappearance of the large trees on the island of Rapa Nui, based on reading the three sources in the unit: a professor's blog post; a review of the book, Collapse, to which the professor's blog post links; and an article entitled "Did Polynesian Rats Destroy Rapa Nui's Large Trees?", which discusses a theory espoused by Collapse and which also presents a new theory. There is no single correct answer to this question; instead, students must compare information across the three pieces of text, evaluate their credibility and logic, and judge the soundness of their claims. Indeed, answers such as "It's too hard to know based on what I've read. I need more information" also received full credit.

Figure 1: RAPA NUI, Item \#7

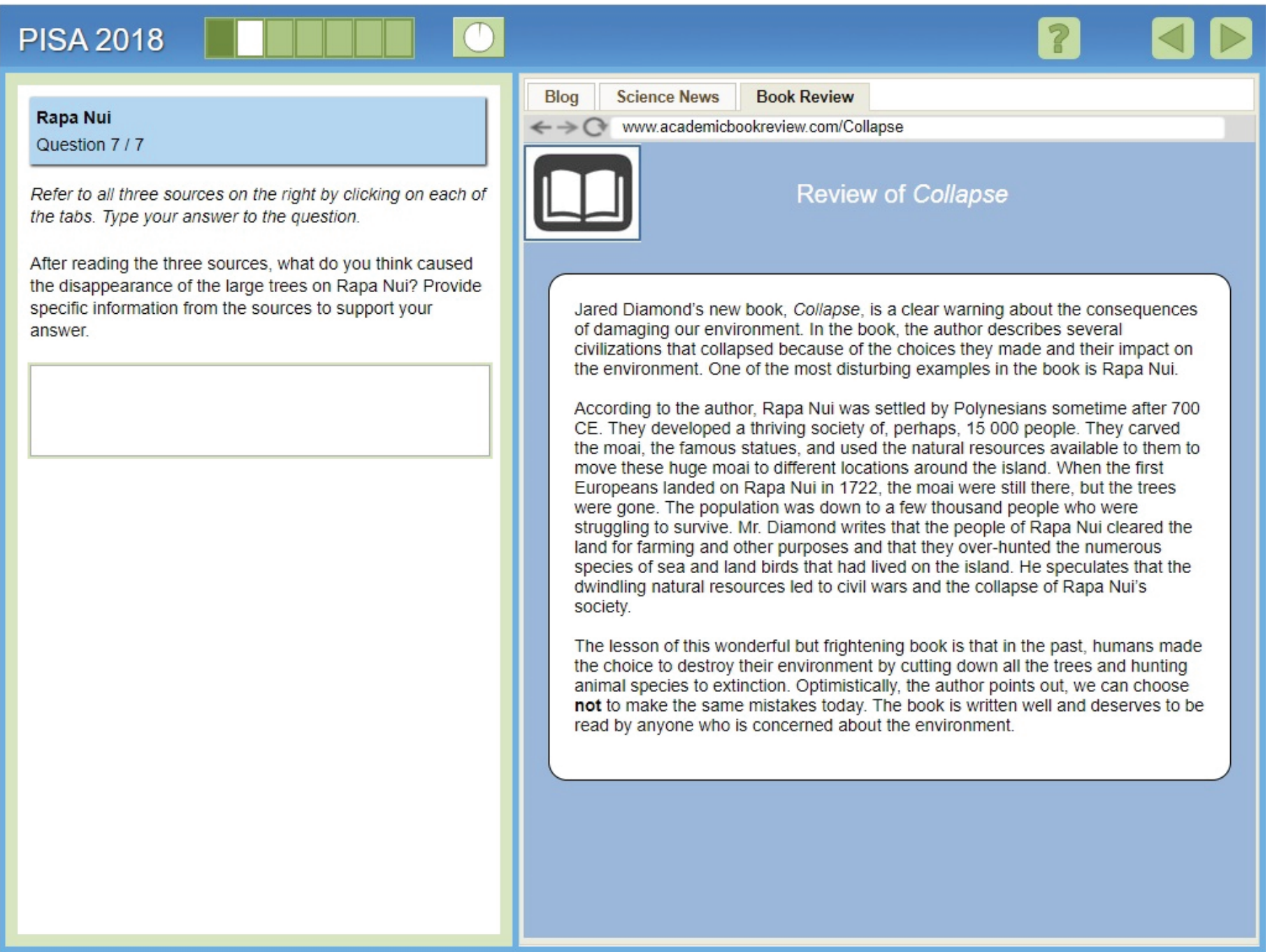


Item 6 from "Rapa Nui" also required students to use multiple sources of text. These sources discussed two competing theories. Students were required to identify the causes of the common effect suggested by each theory and the effect itself. In order to do so, students needed to integrate information from the book review and the news article, which provided the causes; they then needed to identify the effect that was discussed in the sources while disregarding distracting information.

Figure 2: RAPA NUI, Item \#6

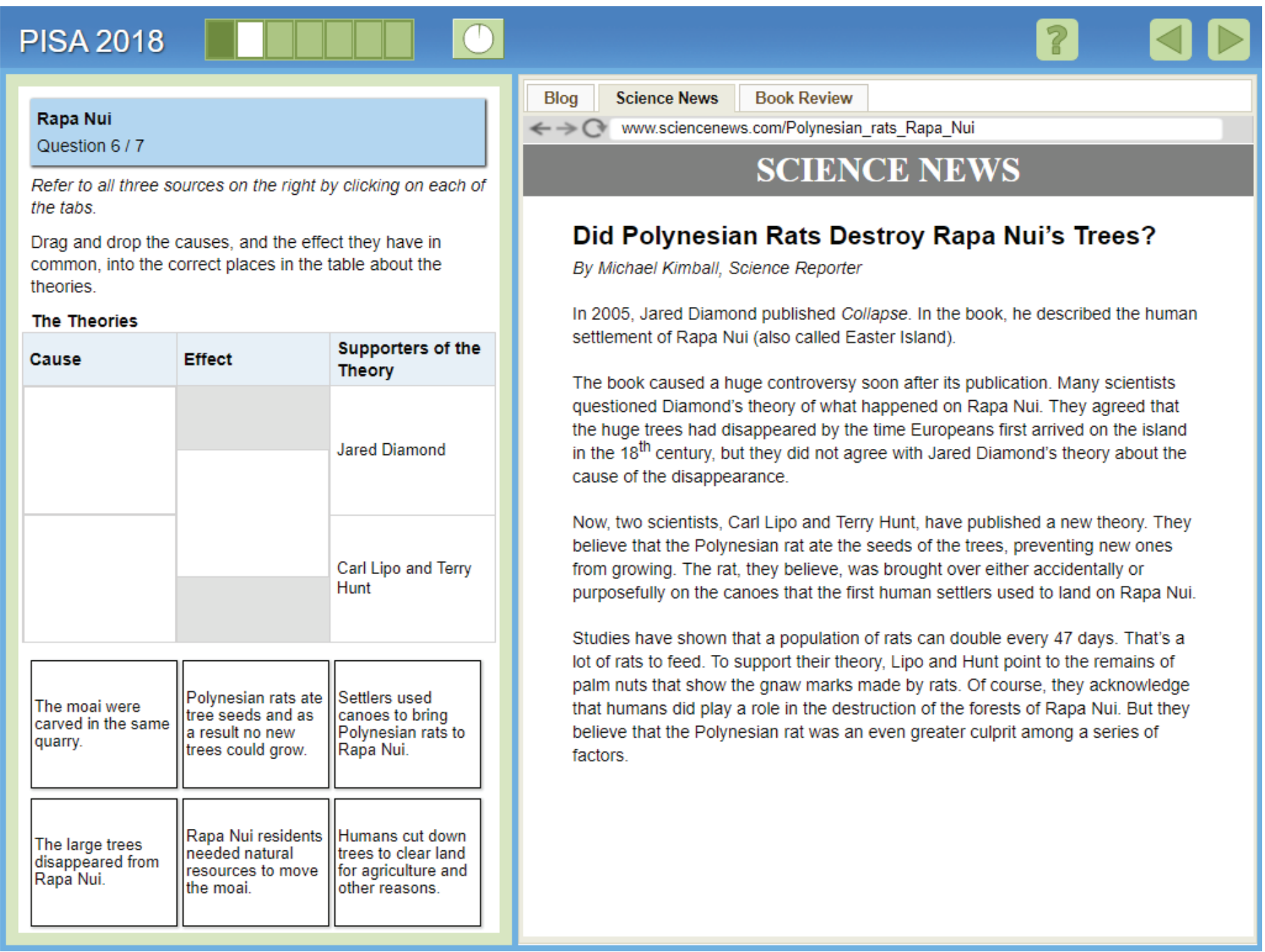

The increased emphasis on the use of multiple sources was not the only change in the PISA 2018 reading assessment. The assessment also evaluated reading fluency, defined as the ease and efficiency with which students read a piece of text, by asking students to determine whether individual sentences made sense. Adaptive testing, which presented students with items targeted to their ability level and thus allowed for a more precise measurement of students' proficiency, was also used. For more details, see the PISA 2018 Assessment and Analytical Framework. 


\section{The bottom line}

The PISA 2018 reading assessment was updated to reflect the evolving nature of how students read, primarily through a greater emphasis on using multiple sources to arrive at the solution. However, PISA still defines reading literacy - the ability to engage with texts - in much the same way as in the past and the results that will be released in December will still provide answers to the questions that educators have been interested in for decades:

- Which countries were able to increase their share of students performing at the highest levels in PISA? Which countries were able to reduce their share of low-performing students?

- In which countries/economies do disadvantaged students have the best chance of overcoming their disadvantage and performing amongst the top students in their country/economy?

- How do students' lives at school relate to their well-being, both in and outside of school?

\section{For more information}

\section{Contact: Jeffrey Mo (Jeffrey.Mo@oecd.org)}

See: OECD (2019), PISA 2018 Assessment and Analytical Framework, PISA, OECD Publishing, Paris, https://doi.org/10.1787/b25efab8-en.

Coming next month: How is reading performance at 15 related to education and labour-market outcomes at 25?

This paper is published under the responsibility of the Secretary-General of the OECD. The opinions expressed and the arguments employed herein do not necessarily reflect the official views of OECD member countries.

This document, as well as any data and map included herein, are without prejudice to the status of or sovereignty over any territory, to the delimitation of international frontiers and boundaries and to the name of any territory, city or area.

This work is available under the Creative Commons Attribution-NonCommercial-ShareAlike 3.0 IGO (CC BY-NC-SA 3.0 IGO). For specific information regarding the scope and terms of the licence as well as possible commercial use of this work or the use of PISA data please consult Terms and Conditions on www.oecd.org. 
